\section{Fórum. O desafio SUS: 20 anos do Sistema Único de Saúde. Introdução}

\author{
Forum. Twenty years of experience and the \\ challenge with the Unified National \\ Health System. Introduction
}

\author{
1 Casa de Oswaldo Cruz, \\ Fundação Oswaldo Cruz, \\ Rio de Janeiro, Brasil. \\ Correspondência \\ M. C. Maio \\ Casa de Oswaldo Cruz, \\ Fundação Oswaldo Cruz. \\ Av. Brasil 4036, Rio de \\ Janeiro, $R J$ \\ 21040-361, Brasil. \\ maio@coc.fiocruz.br
}

\begin{abstract}
This Introduction presents the Forum on the 20 years of experience with the Unified National Health System (SUS), consisting of 3 articles and a postscript. The first article provides a historical overview of the implementation of the SUS, in light of the Constitutional provisions pertaining to health. It discusses the context and main issues underlying the creation of the SUS in Brazil and proposes a renewed linkage between health sector policies and an expanded project for Brazilian society. The second article analyzes the SUS' $d y$ namics; strides in access to and comprehensiveness of care; and challenges for the achievement of its objectives, in light of factors that are external to the system, involving the need for greater politicization of analyses on the issue. The third article approaches social and political processes that developed from 1988 to 2008. It mainly analyzes the history of two collegiate bodies under the SUS at the Federal level: the National Health Council and the Tripartite Inter-Managers' Commission. Despite the complexity identified by the authors and the important obstacles they identify, the reflections indicate that the SUS has been a successful social policy, besides contributing to the consolidation of democracy in Brazil.
\end{abstract}

Single Health System; Health Policy; Health Management
Marcos Chor Maio 1

Nísia Trindade Lima 1

A criação do Sistema Único de Saúde (SUS) tem sido analisada como relevante inovação institucional no campo das políticas sociais, empreendida sob o regime democrático. Na Constituição Federal, promulgada em 1988, afirmou-se a importância de promover a saúde como direito fundamental de cidadania, cabendo ao Estado a obrigação de garanti-la a todos os cidadãos. Sob o preceito constitucional "saúde direito de todos e dever do Estado" defendeu-se a assistência médico-sanitária integral e de caráter universal, com acesso igualitário dos usuários aos serviços, sendo estes hierarquizados e a sua gestão descentralizada. Estabeleceu-se que as ações de saúde deveriam estar submetidas a organismos do executivo com representação paritária entre usuários e demais representantes - do governo, nas suas diversas instâncias, dos profissionais de saúde e dos prestadores de serviços, incluindo-se os do setor privado. Firmaram-se os princípios norteadores do SUS: universalidade; integralidade; participação e descentralização.

As leis posteriores à Constituição, $8.080 \mathrm{e}$ 8.142, ambas de 1990, definiram ordenamentos institucionais que junto às Normas Operacionais Básicas nos anos subseqüentes complementaram a letra constitucional e moldaram o processo de implantação da política. Definiram-se fóruns federativos de negociação e pactuação com assento dos novos atores políticos gerados pelo SUS, tais como as Comissões Intergestoras Bipartite e Tripartite. Foi se forjando uma com- 
plexa engenharia política de representação e articulação de interesses, e moldando-se um desenho institucional sofisticado para a gestão da política descentralizada, em contexto federativo e frente à necessidade de articular autonomia com interdependência dos entes federados. Essa construção institucional do sistema de saúde público tem, inclusive, servido de modelo para a proposição de outras políticas no país, citandose o caso da política de assistência social e, em menor medida, a política de segurança pública. Ao mesmo tempo, uma significativa produção de estudos acadêmicos nas áreas de saúde coletiva, ciências sociais, economia e planejamento vem permitindo que o processo de implantação de uma política seja acompanhado pela análise teórica e empírica dos problemas e desafios colocados. O processo de implementação do SUS tem sido um desafio tanto teórico como prático. No primeiro caso, ele fornece elementos empíricos desafiadores para a elaboração teórica ou para a análise de hipóteses férteis no campo da análise de políticas públicas e da gestão pública, incluindo-se aí a compreensão da dinâmica federativa, das possibilidades de uma gestão democrática, da elucidação das intricadas relações público-privadas, a sustentabilidade política de políticas universais. Do ponto de vista prático, o desafio tem sido o de alcançar a meta de garantir a saúde para todos os cidadãos de forma igualitária.

Este Fórum é resultado dos trabalhos apresentados na mesa-redonda " 20 anos do Sistema Único de Saúde”, realizada durante o 32o Encontro Anual da Associação Nacional de Pós-graduação e Pesquisa em Ciências Sociais (ANPOCS), em outubro de 2008. O Fórum tem como objetivo propiciar o debate sobre a experiência de 20 anos de implantação do SUS, com base em trabalhos recentes realizados por cientistas sociais que vêm contribuindo para maior compreensão sobre esse processo, em suas diversas dimensões: política de saúde como política social; acesso a bens públicos; relações entre setores público e privado; formas de representação política e de participação social. Ao mesmo tempo em que se pretende analisar o campo específico das políticas de saúde, considera-se que a abordagem dessa experiência traz contribuições relevantes para a análise de questões de natureza mais geral e que se referem às relações entre Estado e sociedade na trajetória da democracia brasileira, bem como os processos dinâmicos de formação de políticas públicas.

O artigo de Cohn 1 analisa os 20 anos de implantação do SUS, enfatizando as diretrizes constitucionais na área da saúde. Situa historicamente as principais questões que nortearam a criação do SUS. Em sua conclusão, propõe uma renovada articulação das políticas setoriais com um projeto mais amplo sobre a sociedade, condição sine-qua-non para que a proposta original do SUS não seja capturada por propostas de caráter gerencial.

Menicucci 2 expõe os resultados positivos e os desafios do SUS a partir de um balanço dos alvos alcançados e das restrições à consolidação de suas metas. A autora aborda inicialmente a dinâmica de implantação do SUS, apontando seus limites institucionais e políticos, vistos, em parte, como decorrência de políticas anteriores. Observa os resultados positivos alcançados tanto no que se refere à integralidade da atenção, com efeitos sobre os indicadores de saúde, como às mudanças institucionais que teriam gerado conseqüências favoráveis à administração do sistema. Ressalta os desafios para o alcance dos objetivos e institucionalização das políticas, o que levaria à necessidade de uma maior politização do debate.

Finalmente, Côrtes 3 discorre sobre os processos sociais e políticos que se desenvolveram ao longo da existência do SUS. Centra então sua análise na trajetória de duas instâncias colegiadas do SUS de nível federal: o Conselho Nacional de Saúde (CNS), criado em 1990, e a Comissão Intergestores Tripartite (CIT), constituída em 1993. O surgimento do CNS e do CIT está relacionado a características importantes do perfil institucional do sistema, ou seja, o processo de institucionalização dos instrumentos de participação e a gestão descentralizada. Analisa a importância institucional desses fóruns sobre o cenário político do setor saúde e sobre o desenho das interações entre atores estatais e societais na esfera do SUS. Atenta também para a ação desses atores no âmbito dessas instâncias e fora delas, interessados que estão em ampliar o poder de influência sobre o processo decisório estatal.

Considera-se nos três artigos apresentados que o surgimento do SUS foi um êxito como experimento em matéria de política social no novo regime democrático. Sua origem se confunde com a emergência de um vigoroso movimento no plano da saúde pública em contexto de luta social e política contra a ditadura militar. $\mathrm{O}$ tema da saúde representou, dentre outras reivindicações da sociedade civil como a redução das disparidades sociais, um dos aspectos mais importantes da resistência social e política durante as décadas de 1970 e 1980.

O SUS não é o primeiro capítulo da história da sociedade brasileira em que a saúde pública adquiriu centralidade política quanto ao debate sobre as condições de vida da população. Ao longo da Primeira República, um grupo de sanitaris- 
tas, educadores e engenheiros elegeram o saneamento como via privilegiada para a construção da nacionalidade e da civilização. Nos anos 1950 e 1960, o binômio saúde/desenvolvimento tornou-se questão obrigatória, não obstante a existência de visões distintas sobre o tema. Embora possamos identificar elos de continuidade entre as propostas desses períodos de nossa história e a Reforma Sanitária, iniciada nos anos 1970 cabe destacar que o movimento sanitarista contemporâneo delas se diferencia pela proposição de um agenda articulada em torno da saúde, da democracia e da eqüidade 4 .

\section{Resumo}

Esta introdução apresenta o Fórum sobre os 20 anos do Sistema Único de Saúde (SUS), constituído por três artigos e um posfácio. O primeiro texto faz um balanço da implantação do SUS, considerando as diretrizes constitucionais na área da saúde. Situa o contexto e as principais questões que nortearam a criação do SUS e propõe uma renovada articulação das políticas setoriais com um projeto mais amplo para a sociedade. O segundo analisa a dinâmica do SUS; os avanços no acesso e na integralidade da atenção; $e$ os desafios para a concretização de seus objetivos, em face de fatores externos ao sistema, implicando a necessidade de maior politização das análises sobre o tema. O terceiro artigo aborda processos sociais e políticos que se desenvolveram entre 1988 e 2008. Centra a análise na trajetória de duas instâncias colegiadas do SUS de nível federal: o Conselho Nacional de Saúde e a Comissão Intergestores Tripartite. Em que pese a complexidade apontada pelas autoras e os importantes obstáculos identificados, as reflexões revelam que o SUS foi uma exitosa política social, contribuindo, ao mesmo tempo, para a consolidação da democracia no país.

Sistema Único de Saúde; Política de Saúde; Gestão em Saúde

\section{Colaboradores}

Ambos os autores participaram da redação do texto como resultado da participação na concepção, projeto, análise de literatura pertinente ao tema do Fórum. Os dois autores concordaram quanto à versão final do artigo.
A construção do SUS apresenta-se como um permanente desafio. Em face de sua institucionalização, muitas críticas vêm sendo apresentadas, tanto em fóruns acadêmicos como nos diferentes espaços institucionais onde ocorre a sua efetivação como política social. Os artigos aqui reunidos fazem um consistente balanço e, fundamentalmente, propõem uma agenda para futuras investigações. Esperamos que eles possam contribuir para a avaliação dos resultados alcançados e para as perspectivas de implementação de políticas de saúde adequadas aos princípios do SUS.

\section{Referências}

1. Cohn MA. A reforma sanitária brasileira após 20 anos do SUS: reflexões. Cad Saúde Pública 2009; 25:1614-9.

2. Menicucci TMG. O Sistema Único de Saúde, 20 anos: balanço e perspectivas. Cad Saúde Pública 2009; 25:1620-5.

3. Côrtes SV. Sistema Único de Saúde: espaços decisórios e a arena política de saúde. Cad Saúde Pública $2009 ; 25: 1626-33$.

4. Lima NT, Gerschman S, Edler FC, Suárez JM. Saúde e democracia: história e perspectivas do SUS. Rio de Janeiro: Editora Fiocruz; 2005.

Recebido em 11/Mai/2009

Aprovado em 18/Mai/2009 